\title{
Preliminary outcomes of a paediatric highly active antiretroviral therapy cohort from KwaZulu-Natal, South Africa
} Anand Reddi* ${ }^{* 1}$, Sarah C Leeper*†2, Anneke C Grobler ${ }^{3}$, Rosemary Geddes ${ }^{4}$, K Holly France ${ }^{1}$, Gillian L Dorse ${ }^{1}$, Willem J Vlok ${ }^{1}$, Mbali Mntambo ${ }^{1}$, Monty Thomas ${ }^{1}$, Kristy Nixon ${ }^{1}$, Helga L Holst ${ }^{1}$, Quarraisha Abdool Karim ${ }^{3}$, Nigel C Rollins ${ }^{5}$, Hoosen M Coovadia ${ }^{6}$ and Janet Giddy ${ }^{1}$

\begin{abstract}
Address: ${ }^{1}$ Sinikithemba HIV/AIDS Clinic, McCord Hospital, Durban, South Africa, ${ }^{2}$ Children's Rights Centre, Durban, South Africa, ${ }^{3}$ CAPRISA, Nelson R. Mandela School of Medicine, University of KwaZulu-Natal, Durban, South Africa, ${ }^{4}$ Department of Community Health, Nelson R. Mandela School of Medicine, University of KwaZulu-Natal, Durban, South Africa, ${ }^{5}$ Department of Paediatrics and Child Health, Nelson R. Mandela School of Medicine, University of KwaZulu-Natal, Durban, South Africa and ${ }^{6}$ Doris Duke Medical Research Institute, Nelson R. Mandela School of Medicine, University of KwaZulu-Natal, Durban, South Africa

Email: Anand Reddi* - areddi@fulbrightweb.org; Sarah C Leeper* - sarah.leeper@alumni.duke.edu; Anneke C Grobler - Grobler@ukzn.ac.za; Rosemary Geddes - geddes@ukzn.ac.za; K Holly France - holly@ptnmeth.org.za; Gillian L Dorse - gill@antinomy.co.za; Willem J Vlok - willem.vlok@gmail.com; Mbali Mntambo - mbalidlamuka@webmail.co.za; Monty Thomas - simbenlia@gmx.net; Kristy Nixon - kristy@mccord.co.za; Helga L Holst - holst@mccord.co.za; Quarraisha Abdool Karim - Abdoolq2@ukzn.ac.za; Nigel C Rollins - rollins@ukzn.ac.za; Hoosen M Coovadia - coovadiah@ukzn.ac.za; Janet Giddy - jgiddy@hebron.za.net

* Corresponding authors †Equal contributors
\end{abstract}

Published: 17 March 2007

BMC Pediatrics 2007, 7:13 doi:10.1186/147|-2431-7-13

This article is available from: http://www.biomedcentral.com/|47/-243I/7//3

(c) 2007 Reddi et al; licensee BioMed Central Ltd.

This is an Open Access article distributed under the terms of the Creative Commons Attribution License (http://creativecommons.org/licenses/by/2.0), which permits unrestricted use, distribution, and reproduction in any medium, provided the original work is properly cited.

\begin{abstract}
Background: Few studies address the use of paediatric highly active antiretroviral therapy (HAART) in Africa.

Methods: We performed a retrospective cohort study to investigate preliminary outcomes of all children eligible for HAART at Sinikithemba HIV/AIDS clinic in KwaZulu-Natal, South Africa. Immunologic, virologic, clinical, mortality, primary caregiver, and psychosocial variables were collected and analyzed.
\end{abstract}

Results: From August 31, 2003 until October 31, 2005, 15I children initiated HAART. The median age at HAART initiation was 5.7 years (range 0.3-15.4). Median follow-up time of the cohort after HAART initiation was 8 months (IQR 3.5-13.5). The median change in CD4\% from baseline $(\mathrm{p}<0.00 \mathrm{I})$ was I0.2 (IQR 5.0-13.8) at 6 months $(\mathrm{n}=90)$, and 16.2 (IQR 9.6-20.3) at 12 months $(n=59)$. Viral loads $(V L s)$ were available for 100 children at 6 months of which $84 \%$ had HIV-I RNA levels $\leq 50$ copies $/ \mathrm{mL}$. At 12 months, $80.3 \%(n=61)$ had undetectable VLs. Sixty-five out of 88 children $(73.8 \%)$ reported a significant increase $(p<0.00 \mathrm{I})$ in weight after the first month. Eighty-nine percent of the cohort $(\mathrm{n}$ $=132$ ) reported $\leq 2$ missed doses during any given treatment month (>95\%adherence). Seventeen patients (II.3\%) had a regimen change; two (I.3\%) were due to antiretroviral toxicity. The Kaplan-Meier one year survival estimate was $90.9 \%$ (95\%confidence interval (Cl) 84.8-94.6). Thirteen children died during follow-up (8.6\%), one changed service provider, and no children were lost to follow-up. All 13 deaths occurred in children with advanced HIV disease within 5 months of treatment initiation. In multivariate analysis of baseline variables against mortality using Cox proportional-hazards model, chronic gastroenteritis was associated with death [hazard ratio (HR), 12.34; 95\% Cl, I.27-I I9.7I) and an HIVpositive primary caregiver was found to be protective against mortality [HR, $0.12 ; 95 \% \mathrm{Cl}, 0.02-0.88$ ). Age, orphanhood, baseline CD4\%, and hemoglobin were not predicators of mortality in our cohort. Fifty-two percent of the cohort had at least one HIV-positive primary caregiver, and $38.4 \%$ had at least one primary caregiver also on HAART at Sinikithemba clinic. 
Conclusion: This report suggests that paediatric HAART can be effective despite the challenges of a resource-limited setting.

\section{Background}

In 2005, an estimated 2.3 million children were living with human immunodeficiency virus/acquired immunodeficiency syndrome (HIV/AIDS) worldwide; 700,000 became newly infected, and 570,000 died [1]. Trials in the United States and Western Europe have demonstrated that highly active antiretroviral therapy (HAART) is effective in suppressing HIV viral replication and reversing immunodeficiency in children [2,3]. The result has been a reduction in paediatric hospital admissions and a decrease in morbidity and mortality due to HIV/AIDS [47].

South Africa is home to an estimated 230,000 children infected with HIV/AIDS [8]. Statistics suggest that 50,000 of these children qualify for HAART by World Health Organization (WHO) staging, while only 7,000 have been initiated by the national antiretroviral roll-out program [8]. Despite this large paediatric HIV population, research on care and treatment in this setting is limited. Numerous studies have confirmed the clinical efficacy and feasibility of HAART in adult HIV patients in Africa [9-13] but to date very limited experience address the use of paediatric HAART in Africa. Msellati and colleagues in Côte d'Ivoire, Mbaye et. al in Senegal, Eley et. al., Cowburn et al, and van Kooten Niekerk et al., in South Africa, and the AIDS Working Group of Medecins Sans Frontieres report that good paediatric outcomes can be achieved in Africa [14-19].

Resource-limited settings pose unique challenges to the implementation, effectiveness, and sustainability of HAART programs. Limited availability of paediatric formulations of antiretroviral drugs, weak healthcare infrastructure and the widespread conviction that paediatric specialists are needed to initiate and monitor HAART due to its perceived complexity serve as barriers to comprehensive implementation $[20,21]$. Threats to effectiveness and sustainability in the paediatric population include morbidity and mortality of primary caregivers due to rising HIV prevalence rates, and although the expectation of poor adherence in this setting leading to widespread "antiretroviral anarchy" has not been met, treatment failure and exhaustion of available regimens are ongoing risks [22].

The present study describes a paediatric HAART cohort in KwaZulu-Natal, South Africa. We report preliminary outcomes for 151 children initiated during a 25 month period.

\section{Methods \\ Setting}

KwaZulu-Natal (KZN), the most populous province in South Africa, has the highest HIV-1 adult prevalence rate with the antenatal seroprevalence at 40\% [23]. Tuberculosis (TB) incidence in this setting is 782.2 per 100,000 , and two thirds of HIV patients are co-infected with $\mathrm{TB}[24]$. Fifty percent of the paediatric hospital admissions and $40 \%$ of the under-five mortalities in KZN are HIV related $[25,26]$. Sixty nine percent of children in this province live in poverty, and more than half the children live in households with inadequate water supplies and sanitation [27].

McCord Hospital is a state subsidized urban hospital in Durban, KZN. In 2004, McCord Hospital's Sinikithemba ("We give hope" in IsiZulu) clinic received funding from the United States' President's Emergency Plan for AIDS Relief (PEPFAR) fund for HAART scale-up. This funding subsidizes treatment for all patients. The paediatric copayment is ZAR 60/month ( US\$10) and treatment is free for children whose parents are also receiving HAART at Sinikithemba. Patient co-pay includes all HAART and prophylaxis medication, clinic visits, and laboratory testing allowing all patients in the program to receive 6 monthly CD4 and viral load testing.

Sinikithemba clinic has designed and implemented a family centered model of care. All adults patients accessing HAART are routinely interviewed about their children's health, and those at risk are referred for testing and care. Reciprocally, some children receiving HAART at Sinikithemba have precipitated the diagnosis and subsequent initiation of treatment for their infected primary caregivers. Referred family members are prioritized for HAART enrollment, and families are given clinic appointments for the same day when possible.

\section{Patient selection, preparation, and follow-up}

Clinical and psychosocial selection criteria are identical to the South African Department of Health guidelines for care and treatment of HIV-infected children [28]. To qualify for HAART at Sinikithemba paediatric patients must be symptomatic (WHO clinical stage 3 or 4 ) or have a CD4\% of $<20 \%$ in a child $<18$ months of age or a CD $4 \%$ of $<$ $15 \%$ in a child $>18$ months of age[29]. In addition there must be at least one caregiver who is able to supervise the child's medication and disclosure to another adult living in the same household. The one requirement unique to Sinikithemba is the self-reported ability of the primary 
caregiver to fund treatment monthly. Patients over the age of 16 years were referred to Sinikithemba's adult clinic.

In a process modeled after the South African national program, patient preparation includes three education sessions for caregivers on HIV, HAART and the importance of adherence, as well as a thorough clinical assessment of the child. Baseline laboratory tests include CD4\%, full blood count, liver function tests, urea and electrolytes, and a chest $\mathrm{x}$-ray and/or ultrasound/sputum (when necessary to exclude $\mathrm{TB}$ ). If there are no clinical problems preventing the initiation of HAART, it is prescribed on the day the caregiver finishes the third training session. Antiretroviral therapy is optimally delayed by 2 months for children who present with $\mathrm{TB}$ at baseline [30]. Children return for follow-up visits with doctors 2 weeks post HAART initiation and monthly thereafter.

\section{Treatment}

The South African National Paediatric Antiretroviral Guidelines are used[30], though only brand-name medications are purchased due to PEPFAR's trademark drug regulations. First line, second line, and TB-concurrent HAART regimens are summarized in results. (Some children had regimens other than the South African national plan.) All children are prescribed cotrimoxazole prophylaxis until their CD $4 \%$ is consistently $>20 \%$ for $>6$ months. Ritonavir replaces Kaletra ${ }^{\mathrm{TM}}$ for the duration of concurrent TB treatment in children $<3$ years.

\section{Clinical measurements}

Weight and height are measured at every clinic visit. Children prescribed Kaletra ${ }^{\mathrm{TM}}$ also receive a baseline and 6monthly fasting cholesterol, glucose, and triglycerides assay [30,31]. No baseline viral load (VL) is performed due to cost constraints. CD4\% and VL are performed every 6 months in all children. CD4 lymphocyte counts were performed by flow-cytometry using the FACSCalibur (Becton Dickinson, San Jose, CA, USA) and VL were determined with the Amplicor HIV-1 Monitor PCR test v1.5 (Roche Diagnostics Systems, Branchburg, NJ, USA), with a lower limit of detection of 50 copies of HIV RNA/mL.

\section{Study design and definitions}

This was a retrospective cohort study. The study population consisted of all paediatric patients who were eligible for HAART at Sinikithemba from August 31, 2003 until October 31,2005. Data were collected from clinical charts and from the hospital's electronic patient database system. Deaths were reported by family members to the clinic by use of verbal autopsy [32].

Clinical diagnoses of chronic gastroenteritis and TB were made in accordance with WHO and the South African Department of Health paediatric clinical guidelines [28-
30]. Pneumocystis carinii pneumonia (PCP) was confirmed by chest $\mathrm{x}$-ray and/or (when available) sputum induction for stains to detect Pneumocystis carinii. Lactic acidosis in our clinic is defined as a lactate of $>5 \mathrm{mmol} / \mathrm{l}$ and an arterial blood bicarbonate level of $<20 \mathrm{mmol} / \mathrm{L}$ (or a total venous $\mathrm{C} 02<20 \mathrm{mmol} / \mathrm{l}$ ) with other causes such as septiceaemia and dehydration excluded [33].

Treatment failure that resulted in a change in regimen was defined as a VL > 5000 copies of HIV RNA/ml, for greater than 6 months, resulting in an immunological decline. Genotypic resistance testing was not available to our paediatric cohort due to cost.

A primary caregiver was recorded as a person who has consistently assumed responsibility for the housing, health, or safety of the child [34]. Typically, these were the individuals who completed pre-HAART training, administered medication daily and attended clinic appointments. There was no requirement that the caregiver be the patient's only caregiver or that he/she live with the child. Primary caregivers were designated during a psychosocial intake interview, and changes were noted by clinicians during patient visits. One to three primary caregivers were recorded for each child.

Adherence was assessed by monthly patient self-report of the primary caregiver and child $[35,36]$. A treatment interruption due to poor adherence was defined as three or more consecutive missed daily doses in a treatment month.

Lost to follow-up was defined as no communication between the patient and the clinic staff regarding whereabouts resulting in missing at least 3 monthly follow-up appointments and/or failure to collect medication[37].

\section{Statistical analysis}

Data was analyzed using SAS version 9.1 (SAS Institute Inc., Cary, NC). Patients lost to follow-up or a change in service provider was censored at time of event; while all other patients were censored at time of last clinic visit through October 31,2005. Date of death was taken as endpoint for those patients who died. Changes in median CD4\% were compared by Student's t-test. Weight-for-age Z-scores (WAZ) and Height-for-age Z-scores (HAZ) over time were compared using the Kruskall-Wallis test. WAZ and HAZ scores were calculated by EpiInfo version 3.3.2 based on the Centers for Disease Control (CDC) standardized weight and height curves. The Cox proportionalhazards model was used to assess the relationship between baseline variables and mortality. Variables statistically significant $(\mathrm{p}<0.05)$ in univariate analysis were subsequently tested in multivariate analysis. KaplanMeier survival methods were used to estimate the proba- 
bility of survival from the time of initiation of antiretroviral therapy to death.

\section{Ethics}

The research ethics committee of McCord Hospital and the scientific review committee of CAPRISA, University of KwaZulu-Natal approved this study.

\section{Sources of Funding}

United States' President's Emergency Plan for AIDS Relief (PEPFAR) fund administered by the Elizabeth Glaser Paediatric AIDS Foundation (EGPAF). PEPFAR funding was only used for care and treatment of paediatric patients. PEPFAR and EGPAF did not contribute intellectually towards this publication.

\section{Results Study cohort}

From August 31, 2003 until October 31, 2005, 151 children initiated HAART at Sinikithemba. Thirteen children died during follow-up $(8.6 \%)$, one changed service provider, and no children were lost to follow-up. Median follow-up time of the cohort after HAART initiation was 8 months (IQR 3.5-13.5).

\section{Baseline characteristics (presented in Table I)}

The majority of the cohort had advanced HIV disease at initiation of treatment as indicated by their WHO clinical stage, $\mathrm{CD} 4 \%$ ( $\mathrm{n}=146,5$ missing values), and baseline anthropometry.

Fifty children (33.1\%) had TB at baseline: 35 pulmonary, 13 extrapulmonary and two concurrent pulmonaryextrapulmonary.

At commencement of HAART, 119 children (78.8\%) were antiretroviral naïve, $19(12.6 \%)$ had received HAART previously at another site, and $13(8.6 \%)$ had a failed prevention of mother-to-child transmission (PMTCT) intervention.

Initial HAART regimens of the cohort are presented in Table 2.

\section{Primary Caregivers}

The 151 children were cared for by 214 familial and nonfamilial primary caregivers as presented in Figure 1. The distribution of HIV-positive caregivers was not limited to a few households as $52.3 \%$ of children had at least one HIV-positive caregiver, and $38.4 \%$ of children had at least one primary caregiver also in care at Sinikithemba.

\section{Treatment responses}

Immunologic and virologic responses to HAART are presented in Figure 2. Children that initiated HAART in the 6 months prior data censure did not have a 6-monthly CD4\% and VL result available. All children reaching a 6 month or 12 month endpoint had CD4\% and VL. The cohort's median change in CD4\% from baseline was 10.2 (IQR 5.0-13.8) at 6 months (p < 0.001), and 16.2 (IQR 9.6-20.3) at 12 months $(\mathrm{p}<0.001)$. At the time of publication VLs were available for 100 children at 6 months, of which $84 \%$ (95\%CI 80.3-87.7) were undetectable. At 12 months 61 children had available VLs, and $80.3 \%$ (95\%CI 75.2-85.4) of these were undetectable. The cohort's median changes from baseline to last available WAZ and HAZ scores were 1.0 and 0.4 , respectively, after an average of 8.9 months. The change was statistically significant for WAZ (Kruskall-Wallis test $\mathrm{p}<0.0001$ ) but not for the HAZ score (Kruskall-Wallis test $\mathrm{p}=0.2880$ ). Sixtyfive out of 88 children $(73.8 \%)$ reported a significant increase $(\mathrm{p}<0.001)$ in WAZ score after the first month.

\section{Mortality}

In univariate analysis of baseline variables against mortality, significant hazard ratios were associated with WHO clinical stage 4 , weight-for-age $<$ fifth percentile, and baseline presence of: $\mathrm{TB}$, chronic gastroenteritis, pneumonia, and PCP. Loss of one or two parents was not significantly associated with mortality. In multivariate analysis, chronic gastroenteritis was significantly associated with death and the presence of an HIV-positive primary caregiver was found to be protective. These data are presented in Table 3.

The Kaplan Meier (presented in Figure 3) mortality survival estimate at 12 months was $90.9 \%$ (95\%CI $84.8-$ 94.6). Paediatric mortalities are summarized in Table 4. All 13 deaths occurred within the first 5 months of HAART initiation. No deaths were attributed to metabolic disorders or other drug-related adverse effects. Autopsy data were not available, but the most commonly reported causes of death were chronic gastroenteritis $(n=6)$ and TB $(n=4)$. Other causes of death included: sepsis syndrome $(n=1)$, suspected PCP $(n=1)$, and a respiratory tract infection $(n=1)$.

\section{Regimen durability}

One hundred and thirty-four patients (88.7\%) are still on their first Sinikithemba HAART regimen. Fifteen $(9.9 \%)$ have progressed to a second line, one $(0.7 \%)$ to a third line, and one $(0.7 \%)$ to a fourth line. Of the $17(11.3 \%)$ that had a regimen change, only two were due to antiretroviral toxicity. One child discontinued zidovudine because of anemia, and one child stopped stavudine because of lactic acidosis. Seven regimen changes due to treatment failure were recorded. Initiation or completion of $\mathrm{TB}$ treatment resulted in six children changing regimens. Two children switched from Kaletra ${ }^{\mathrm{TM}}$ to Efavirenz with increasing age ( $>3$ years). 
Table I: Baseline characteristics of the Sinikithemba paediatric cohort

\begin{tabular}{|c|c|}
\hline Demography & [n (\%)] \\
\hline Children & $|5|$ \\
\hline Female & $77(51.0 \%)$ \\
\hline \multicolumn{2}{|l|}{ Age } \\
\hline$<3$ years & 39 (25.8\%) \\
\hline $3-5$ years & $43(28.5 \%)$ \\
\hline $6-8$ years & $43(28.5 \%)$ \\
\hline$\geq 9$ years & $26(17.2 \%)$ \\
\hline Median years [range] & $5.7[.3-15.4]$ \\
\hline Parent status & [n (\%)] \\
\hline Two parents alive & 67 (44.4\%) \\
\hline Only father living & $19(12.6 \%)$ \\
\hline Only mother living & 27 (I7.9\%) \\
\hline Neither parent living & $38(25.1 \%)$ \\
\hline WHO clinical stage [n (\%)] & {$[n(\%)]$} \\
\hline Stage I & $26(17.2 \%)$ \\
\hline Stage 2 & $19(12.6 \%)$ \\
\hline Stage 3 & $72(47.7 \%)$ \\
\hline Stage 4 & $34(22.5 \%)$ \\
\hline Anthropometry & Median (IQR) \\
\hline Weight-for-age Z-score & $-1.9(-3.6$ to -0.9$)$ \\
\hline Height-for-age Z-score & $-2.2(-3.0$ to -1.1$)$ \\
\hline CD4 lymphocyte \% & {$[\mathrm{n}(\%)]$} \\
\hline$<5 \%$ & $52(35.6 \%)$ \\
\hline $5 \%-9 \%$ & $36(24.7 \%)$ \\
\hline $10 \%-14 \%$ & $28(19.2 \%)$ \\
\hline $15 \%-24 \%$ & $26(17.8 \%)$ \\
\hline$>25 \%$ & $4(2.7 \%)$ \\
\hline Median CD4\% (IQR) & $7.4(2.1-13.7)$ \\
\hline Laboratory values & Median (IQR) \\
\hline Albumin $(g / L)$ & $30.0(26.0-35.0)$ \\
\hline ALT (IU/L) & $18.0(\mid 4.0-28.3)$ \\
\hline Hemoglobin (g/dl) & $10.1(8.9-11.0)$ \\
\hline Tuberculosis & [n (\%)] \\
\hline Present & $50(33.1 \%)$ \\
\hline Other opportunistic infections & {$[n(\%)]$} \\
\hline Chronic gastroenteritis & $52(34.4 \%)$ \\
\hline Pneumonia & $13(8.6 \%)$ \\
\hline Oesophageal candidiasis & $13(8.6 \%)$ \\
\hline PCP & II (7.3\%) \\
\hline Cryptococcal meningitis & I (0.7\%) \\
\hline $\mathrm{CMV}$ retinitis & 0 \\
\hline Toxoplosmosis & 0 \\
\hline
\end{tabular}

\section{Adherence}

Ninety patients (59.6\%) reported no missed doses for the duration of their treatment. Forty-two (27.8\%) children reported "some missed doses" during at least one month of treatment, not exceeding 2 missed doses per month (> $95 \%$ adherence). Sixteen (10.6\%) reported one or more treatment interruptions. Adherence data was missing for 3 children. Common reasons reported for missed doses were: financial trouble that prevented caregivers from collecting medication on time, vomiting of medication without re-dosing, incorrect dosing by a caregiver, missed clinic appointments and pharmacy collections, confusion between multiple caregivers, and child refusal or self-discontinuation.

\section{Disclosure}

At the time that the data was censored, 12 (7.9\%) children had been made aware of their own HIV+ status: $0 \%$ of children $<3$ years of age $(n=0), 2.4 \%$ of children $3-5$ years $(n=1), 7.5 \%$ of children $6-8$ years $(n=3), 25 \%$ of children 9-11 years $(n=3)$ and $83 \%$ of children $12-15$ years $(n=5)$. Children who had not been disclosed to were given partial, inaccurate, or no information by caregivers. 
Table 2: Initial Antiretroviral Regimens

\begin{tabular}{|c|c|c|c|c|c|c|}
\hline \multirow[t]{2}{*}{ Age } & \multirow[t]{2}{*}{ Regimen } & \multirow[t]{2}{*}{ NRTIs } & \multicolumn{4}{|c|}{ NNRTI/PI } \\
\hline & & & EFV & NVP & Kaletra $^{\mathrm{TM}}$ & RTV \\
\hline \multirow[t]{3}{*}{$<3$ years $(n=39)$} & | st line & $\mathrm{d} 4 \mathrm{~T} / 3 \mathrm{TC}$ & 7 & 1 & 23 & 0 \\
\hline & $2^{\text {nd }}$ line & AZT/ddl & 0 & 0 & 0 & 0 \\
\hline & $\mathrm{TB}$ & $\mathrm{d} 4 \mathrm{~T} / 3 \mathrm{TC}$ & 0 & 0 & 0 & 5 \\
\hline \multirow[t]{3}{*}{$\geq 3$ years $(n=112)$} & $\left.\right|^{\text {st }}$ line & $\mathrm{d} 4 \mathrm{~T} / 3 \mathrm{TC}$ & 61 & 0 & 1 & 0 \\
\hline & $2^{\text {nd }}$ line & AZT/ddl & 1 & 0 & I & 0 \\
\hline & $\mathrm{TB}$ & $\mathrm{d} 4 \mathrm{~T} / 3 \mathrm{TC}$ & 37 & 0 & 1 & 2 \\
\hline
\end{tabular}

ARV, antiretroviral therapy

d4T, stavudine; 3TC, lamivdine; AZT, zidovudine;

ddl, didanosine; EFV, efavirenz; RTV, Ritonavir

\section{Discussion \\ Limitations}

The Sinikithemba self-pay requirement may have resulted in a selection bias towards patients with greater financial resources. However, their decision to seek semi-private subsidized care may instead reflect limited access to HAART in the public sector, where province-wide paediatric enrollment is stunted due to long waiting lists, staff shortages, laboratory backups, etc. Fifty-six percent of our cohort is living well below the national poverty line, as indicated by their eligibility for a government welfare grant which requires a combined household income of less than ZAR 800/month ( US\$134). More research is necessary to understand the financial constraints of this population, but limited validity of this data due to financial inequity cannot be assumed.

CD4 and VL laboratory results were available for all children who reached a 6 or 12 month endpoint, however no values were recorded for patients initiated in the 6 months prior to data censure. The follow-up time of the cohort was insufficient to confirm the long-term efficacy of HAART in this setting, although good short-term outcomes are indicated. To date this paediatric cohort is the largest in Africa to be documented in the literature; however, there were relatively few deaths to be included within the univariate and multivariate analyses.

\section{Analysis}

We have documented the initial experiences of 151 paediatric HIV patients initiating HAART in KZN, South Africa. Our data suggests that a family-centered paediatric HAART program in a resource-limited setting can be both clinically effective and sustainable as demonstrated by therapeutic responses, survival, patient retention, and regimen durability.

The Sinikithemba paediatric cohort's immunologic and anthropometric responses to HAART were comparable to the other paediatric cohorts in Africa as well as the United
States and Europe [14-16,38]. Eighty-six out of 90 (95.6\%) children at 6 months and 57 out of 59 (96.6\%) children at 12 months had an increase in CD4\% from baseline. In developing-world settings where CD4 monitoring is not available due to cost, weight has been used as a prognostic indicator of clinical effectiveness of HAART $[39,40]$. By this measure, the Sinikithemba cohort demonstrated an immediate and significant response to therapy: 65 out of 88 children (73.8\%) reported a significant increase in WAZ score after the first month following HAART. The significant change in the cohort's WAZ scores but not HAZ scores is to be expected given the abbreviated follow-up time of our study $[14,41,42]$.

The Sinikithemba cohort exhibited high degrees of virologic suppression: $84.0 \%$ at 6 months and $80.3 \%$ at 12 months. In Côte d'Ivoire, $49.3 \%$ of children $(\mathrm{n}=73)$ achieved virologic suppression $(<250$ copies $/ \mathrm{mL}$ ) after 12 months [14]. In South Africa, after 12 months of HAART $69.7 \%$ of children $(n=264)$ had a viral load $<400$ copies/ $\mathrm{ml}$ [43]. In the United States in a multi-site paediatric cohort of 263 children, Ruthstein et al reported a rate of $34 \%$ virologic suppression $(<400$ copies $/ \mathrm{mL})$ at 12 months[44]. Both the Côte d'Ivoire (mean age: 7.2 yrs, age range $0.7-15.2$ yrs) and the cohort reported by Ruthstein et. al (mean age: $8.5 \mathrm{yrs}$, age range $0-17 \mathrm{yrs}$ ) had similar age ranges compared to the Sinikithemba cohort. There are differences between the Sinikithemba cohort and other paediatric studies (such as different populations, viral subtypes, HAART regimens, etc.), which render conclusions drawn from direct comparisons to be guarded. It may also be possible that the Sinikithemba cohort has higher rates of adherence which may contribute to more effective virologic suppression $[45,46]$. More research is necessary to investigate the sources of this discrepancy.

The Sinikithemba mortality rate of $8.6 \%$ compares favorably with other paediatric cohorts in the developing world (ranges 7.0\%-20.0\%) [14-16]. Although we have shown that the baseline presence of many WHO clinical stage 4 


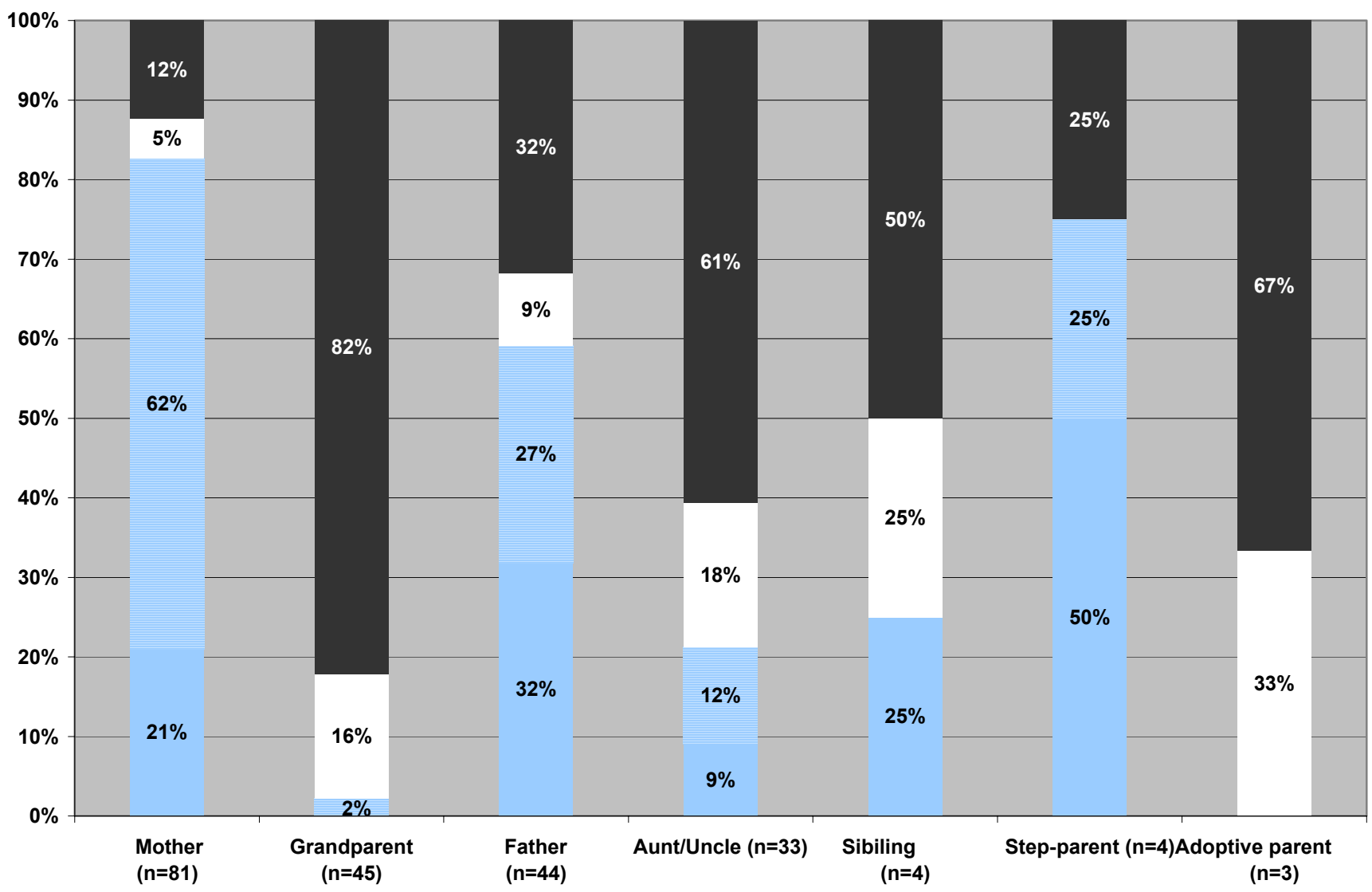

HIV+, not in care at Sinikithemba Clinic

HIV+, in care at Sinikithemba Clinic

HIV-

HIV status unknown/untested

\section{Figure I}

HIV status and HAART in the primary caregivers of the Sinikithemba paediatric cohor: The Sinikithemba cohort was cared for by 2I4 familial and non-familial primary caregivers. Of these 214 primary caregivers; 105 (49.1\%) had tested positive for HIV of whom 68 (64.8\%) were also receiving HAART at Sinikithemba, 86 (40.2\%) were unaware of their status, and 23 ( $10.7 \%)$ had tested HIV negative. Ten children were in institutional care (orphanage), no primary caregiver identified.

symptoms have a higher hazard ratio for mortality; age, orphanhood, baseline CD4\%, and hemoglobin were not predicators of mortality in our cohort as they were in other published African cohorts [9-11,47,48].

No children were lost to follow-up, despite much of the cohort having to contend with long travel distances, multiple caregivers, and self-funding responsibilities. Adequate follow-up data from other paediatric cohorts is not available; however, this rate contrasts sharply with data from African adults cohorts, which have a weighted mean of $79.8 \%$ patient retention at 12 months[12]. There are several plausible reasons for this. The immediate improvement in most of the cohort (nearly three-quarters reporting significant weight gain in the first month) may have convinced caregivers of the effectiveness of HAART and the need for ongoing care. Finally, treating caregivers and children at the same site may create stronger ties to families resulting in better retention.

Harries et al. summarize the clinical arguments against the sustainability of HAART by advising HAART programs in 


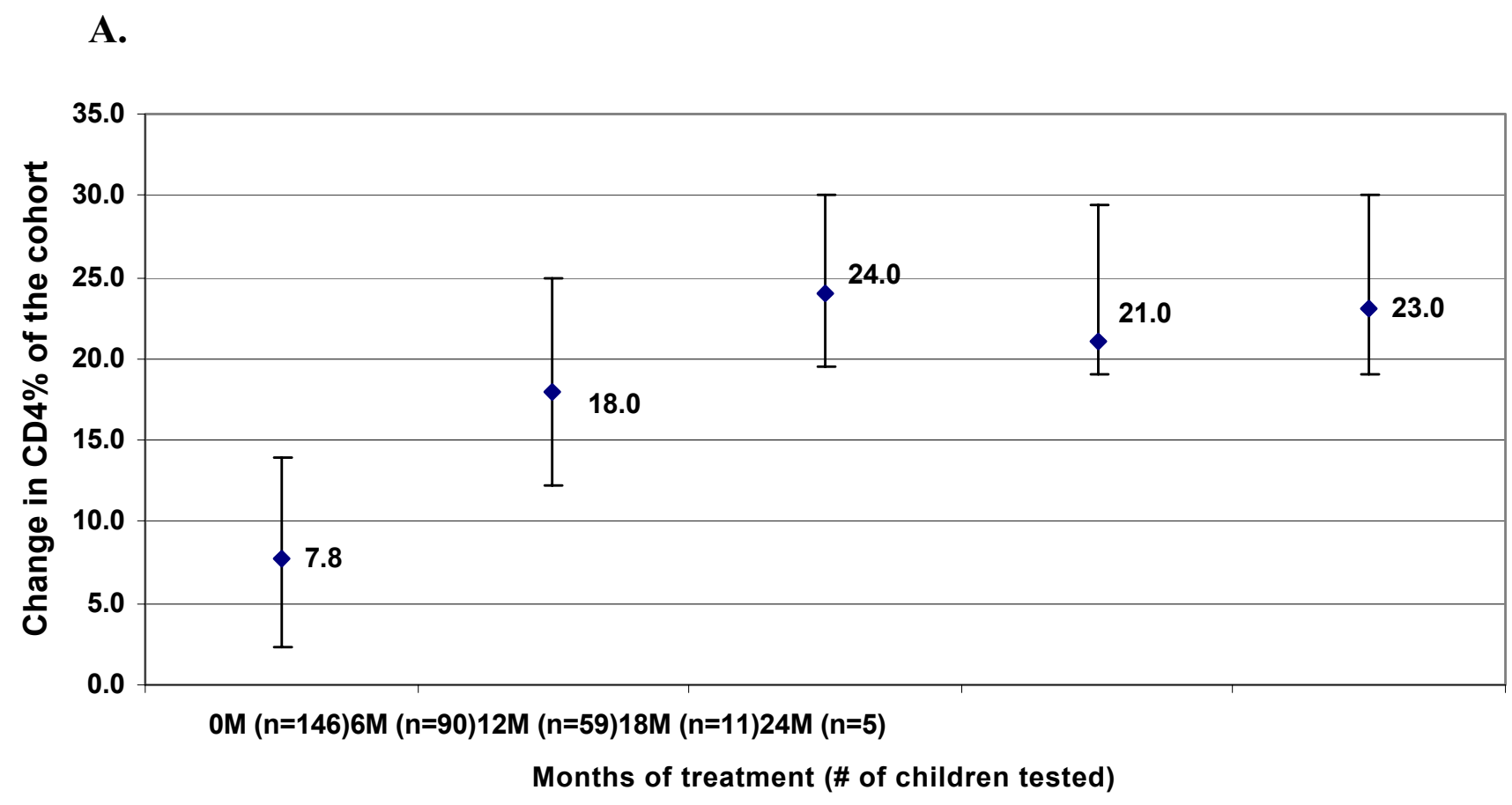

B.

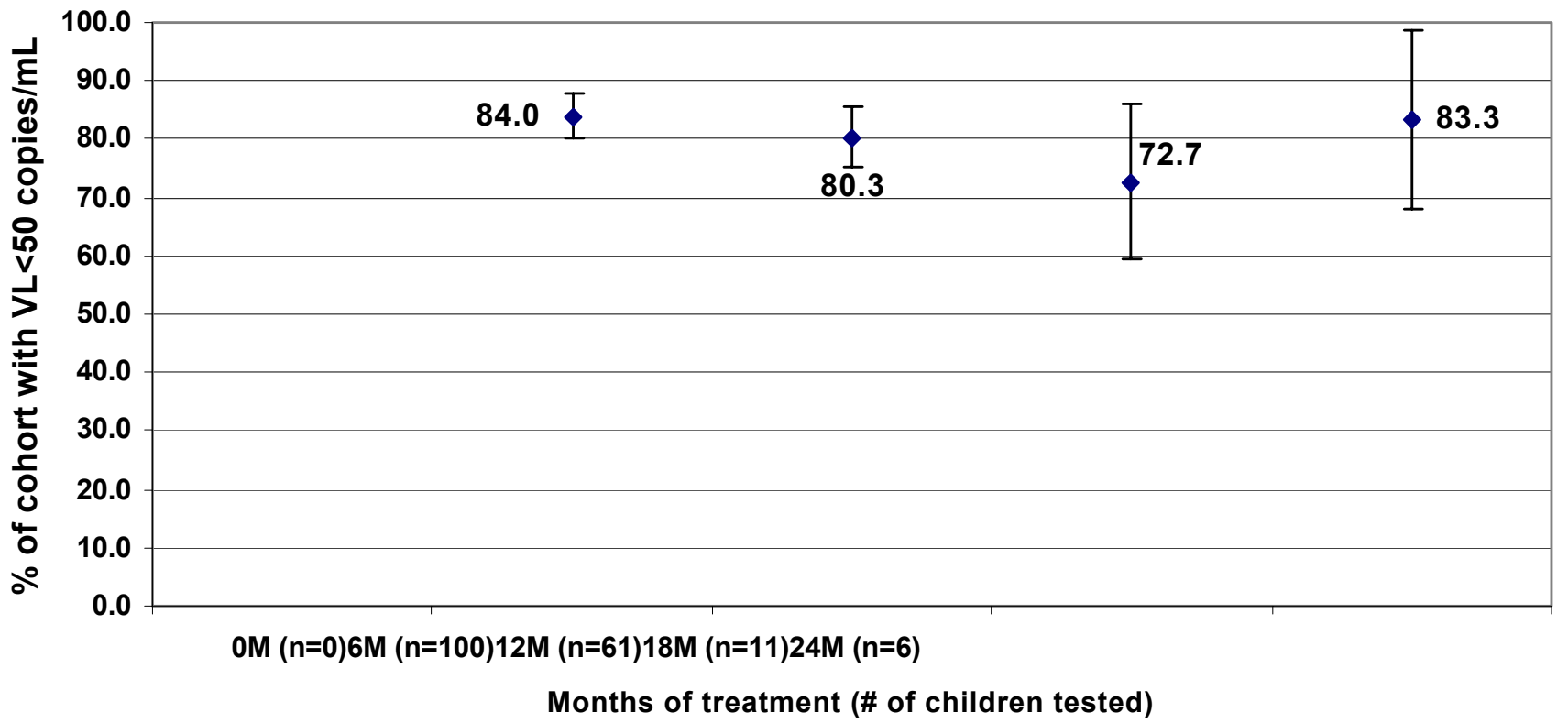

Figure 2

CD4\% and Viral Loads changes of the Sinikithemba paediatric cohort in response to HAART: A. Median increase in CD4\% from baseline. The vertical bars in subfigure A indicate IQR. B. Percentage of cohort achieving undetectable viral loads. The vertical bars in subfigure B indicate $95 \% \mathrm{Cl}$.

resource-limited areas that they would be "prudent to decide what drugs might be used for salvage antiretroviral therapy when (author's emphasis) drug resistance, side- effects, or both become a problem."[22] However, only two children at Sinikithemba (1.3\%) experienced an adverse event that required a regimen change, a rate simi- 
Table 3: Mortality: Cox proportional hazards models between baseline characteristics and death

\begin{tabular}{|c|c|c|c|c|c|}
\hline \multirow[b]{2}{*}{ Baseline Characteristic } & \multirow[b]{2}{*}{ No. of Deaths } & \multicolumn{2}{|l|}{ Univariate analysis } & \multicolumn{2}{|l|}{ Multivariate analysis } \\
\hline & & Hazard ratio $95 \% \mathrm{Cl}$ & $p$ & Hazard ratio $95 \% \mathrm{Cl}$ & $p$ \\
\hline \multicolumn{6}{|l|}{ Gender } \\
\hline Male & 6 & 1.00 & & 1.00 & - \\
\hline Female & 7 & $1.14(0.38-3.40)$ & 0.810 & $2.78(0.66-11.86)$ & 0.163 \\
\hline \multicolumn{6}{|l|}{ Age } \\
\hline$<3$ yrs & 5 & 1.00 & & 1.00 & - \\
\hline $3-5$ yrs & 2 & $0.35(0.07-1.8 \mathrm{I})$ & 0.210 & $1.37(0.21-9.04)$ & 0.747 \\
\hline $6-8$ yrs & 3 & $0.52(0.12-2.16)$ & 0.365 & $0.25(0.02-2.93)$ & 0.268 \\
\hline$\geq 9 \mathrm{yrs}$ & 3 & $0.92(0.22-3.85)$ & 0.908 & $2.18(0.44-10.85)$ & 0.342 \\
\hline \multicolumn{6}{|l|}{ WHO clinical stage } \\
\hline Stage $1-3$ & 7 & 1.00 & & 1.00 & - \\
\hline Stage 4 & 6 & $3.01(1.01-8.95)$ & $0.048 *$ & I.82 (0.4I-8.03) & 0.430 \\
\hline \multicolumn{6}{|l|}{ Weight (**2 missing values) } \\
\hline$\geq 5$ Percentile & 1 & 1.00 & & 1.00 & - \\
\hline$<5$ Percentile & 10 & $8.60(1.10-67.15)$ & $0.040 *$ & $4.96(0.45-55.31)$ & 0.193 \\
\hline \multicolumn{6}{|l|}{ CD4\% (**I missing value) } \\
\hline$\geq 5 \%$ & 5 & 1.00 & & - & - \\
\hline$<5 \%$ & 7 & $2.65(0.84-8.34)$ & 0.097 & - & - \\
\hline \multicolumn{6}{|l|}{ Tuberculosis } \\
\hline Absent & 5 & 1.00 & & 1.00 & - \\
\hline Present & 8 & $3.39(1.11-10.37)$ & $0.032 *$ & $1.08(0.25-4.59)$ & 0.919 \\
\hline \multicolumn{6}{|l|}{ Pulmonary } \\
\hline Absent & 9 & 1.00 & & - & - \\
\hline Present & 4 & $1.53(0.47-5.01)$ & 0.480 & - & - \\
\hline \multicolumn{6}{|l|}{ Extrapulmonary } \\
\hline Absent & 10 & 1.00 & & - & - \\
\hline Present & 3 & $3.06(0.84-11.20)$ & 0.091 & - & - \\
\hline \multicolumn{6}{|l|}{ Chronic gastroenteritis } \\
\hline Absent & 3 & 1.00 & & 1.00 & - \\
\hline Present & 10 & $6.69(1.84-24.30)$ & $0.004 *$ & $12.34(1.27-1|9.7|)$ & $0.030 *$ \\
\hline \multicolumn{6}{|l|}{ Pneumonia } \\
\hline Absent & 9 & 1.00 & & 1.00 & - \\
\hline Present & 4 & $5.23(1.61-16.98)$ & $0.006 *$ & $4.03(0.79-20.54)$ & 0.094 \\
\hline \multicolumn{6}{|l|}{ PCP } \\
\hline Absent & 10 & 1.00 & & 1.00 & - \\
\hline Present & 3 & $3.81(1.05-13.86)$ & $0.042 *$ & $5.35(0.84-33.86)$ & 0.075 \\
\hline \multicolumn{6}{|l|}{ Oesophageal candidiasis } \\
\hline Absent & 12 & 1.00 & & - & - \\
\hline Present & 1 & $0.92(0.12-7.04)$ & 0.932 & - & - \\
\hline \multicolumn{6}{|l|}{ Hemoglobin } \\
\hline$>10 \mathrm{~g} / \mathrm{dl}$ & 5 & 1.00 & & - & - \\
\hline$\leq 10 \mathrm{~g} / \mathrm{dl}$ & 8 & $1.87(0.61-5.73)$ & 0.272 & - & - \\
\hline \multicolumn{6}{|l|}{ Primary caregiver HIV Status } \\
\hline HIV negative or unknown & 10 & 1.00 & - & 1.00 & - \\
\hline HIV positive & 3 & $0.26(0.07-0.95)$ & $0.04 I^{*}$ & $0.12(0.02-0.88)$ & $0.037 *$ \\
\hline \multicolumn{6}{|c|}{ Primary caregiver receiving HAART at Sinikithemba } \\
\hline Primary caregiver not in care & 12 & 1.00 & - & - & - \\
\hline Primary caregiver in care & I & $0.13(0.02-1.01)$ & 0.051 & - & - \\
\hline \multicolumn{6}{|l|}{ Parent status } \\
\hline Two parent alive & 6 & 1.00 & - & - & - \\
\hline One parent alive & 4 & $0.92(0.26-3.26)$ & 0.896 & - & - \\
\hline Neither parent living & 3 & $0.82(0.21-3.28)$ & 0.778 & - & - \\
\hline
\end{tabular}

lar to paediatric results from Côte d'Ivoire and substantially lower than the percentages recorded for African adult cohorts (range 14.3\%-80.2\%) [12,14]. We have not conducted structured adherence analysis, but patient selfreport data, high rates of viral suppression, and low incidence of treatment failure indicate that adherence levels were not a threat to regimen durability or an obstacle to good clinical outcomes in this cohort [45].
Other paediatric HAART studies in Africa have analyzed the rates of orphanhood within their cohorts, but to our knowledge none have recorded the HIV-status of the primary caregivers or analyzed the outcomes associated with HIV-positive caregivers [34]. Our data shows that although more than half of the Sinikithemba cohort is cared for by at least one HIV-positive caregiver, these caregivers showed a protective effect against mortality when compared with caregivers who were untested or HIV neg- 


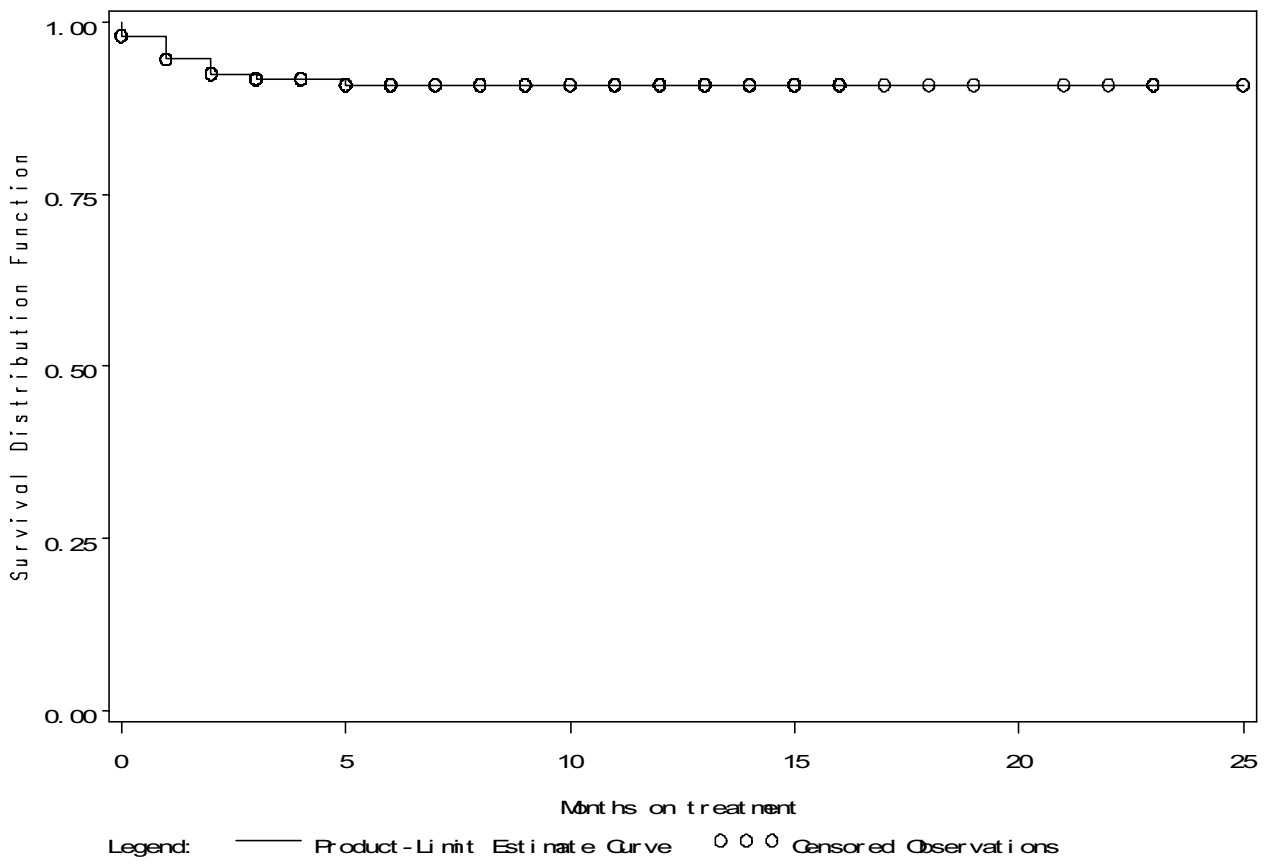

\begin{tabular}{|l|c|c|c|c|c|c|c|c|c|c|c|}
\hline Month & 0 & 1 & 2 & 3 & 4 & 5 & 6 & 9 & 12 & 18 & 24 \\
\hline No. at risk & 151 & 144 & 135 & 124 & 113 & 105 & 100 & 73 & 61 & 11 & 6 \\
\hline Deaths & 0 & 3 & 5 & 3 & 1 & 1 & 0 & 0 & 0 & 0 & 0 \\
\hline \% Surviving & 100.0 & 98.0 & 94.6 & 92.5 & 91.8 & 90.9 & 90.9 & 90.9 & 90.9 & 90.9 & 90.9 \\
\hline $95 \%$ CI & & $94.0-99.4$ & $89.5-97.3$ & $86.9-95.8$ & $85.9-95.2$ & $84.8-94.6$ & $84.8-94.6$ & $84.8-94.6$ & $84.8-94.6$ & $84.8-94.6$ & $84.8-94.6$ \\
\hline
\end{tabular}

Figure 3

Kaplan-Meier mortality survival curve of the cohort.

ative. We hypothesize that HIV-positive primary caregivers on HAART at the same site may be able to provide more informed treatment support for their children resulting in better outcomes. Those HIV positive caregivers not yet on HAART may still be more knowledgeable about symptom management and disease progression, more experienced with health care systems and/or more likely to access available health services. Further research is necessary to investigate these possibilities, but the necessity of supporting all caregiver/dependent relationships is clear.

\section{Conclusion}

Many settings in Africa, with social and economic constraints placed on children, demand thoughtful and sensitive management of HIV-positive children on HAART. Despite this, we have shown that a cohort with advanced HIV disease in this setting responds favorably to treatment.

All 13 deaths occurred in children with advanced HIV disease within 5 months of treatment initiation. This suggests that a greater effort should be made to identify and treat HIV-positive children at an earlier stage of their infection, and that children with advanced disease should be closely monitored and supported at the onset of HAART. Based on these data we suggest that these children, especially those who present with chronic gastroenteritis which may interfere with uptake/absorption of the medications, be referred to paediatric inpatient wards or a local palliative (step-down) care center for HAART initiation. Treatment counselors can conduct home visits to monitor and support caregivers, especially those with little treatment experience.

A third of our cohort presented with TB at baseline and four deaths were TB related. With such a high prevalence in this setting, more research on paediatric HIV/TB coinfection is necessary, especially with regard to immune reconstitution syndrome, multi-drug resistance, and bestpractice guidelines for concurrent and/or sequential HAART/TB treatment in order to minimize drug toxicity and optimize outcomes $[9,24]$.

The high rate of HIV positive caregivers indicates that it is imperative to transform the paediatric treatment model 
Table 4: Baseline biological characteristics of children who died

\begin{tabular}{|c|c|c|c|c|c|c|c|c|c|c|c|}
\hline Pt\# & Sex & $\begin{array}{l}\text { Age } \\
\text { (Yrs) }\end{array}$ & $\begin{array}{l}\text { WHO } \\
\text { Stage }\end{array}$ & WAZ & CD4\% & ARV Regimen & $\begin{array}{l}\text { ARV time to death } \\
\text { (weeks) }\end{array}$ & ALB(g/L) & ALT(IU/L) & $\operatorname{HGB}(g / d l)$ & Suspected cause of death \\
\hline I & M & 0.3 & 4 & - & $37.6 \%$ & $\mathrm{~d} 4 \mathrm{~T} / 3 \mathrm{TC} / \mathrm{Kal}$ & 09 & 25.0 & 14.0 & 9.9 & Chronic gastroenteritis \\
\hline 2 & $\mathrm{~F}$ & 7.5 & 4 & -9.52 & $7.9 \%$ & AZT/3TC/EFV & 20 & 18.0 & 33.0 & 10.7 & TB Miliary \\
\hline 3 & $\mathrm{~F}$ & 9.8 & 4 & -4.34 & $0.8 \%$ & $\mathrm{~d} 4 \mathrm{~T} / 3 \mathrm{TC} / \mathrm{EFV}$ & 14 & 30.0 & 12.0 & 7.9 & TB Adenopathy \\
\hline 4 & $M$ & 3.0 & 4 & -4.81 & - & $\mathrm{AZT} / 3 \mathrm{TC} / \mathrm{Kal}$ & 10 & - & - & 9.1 & TB Lymph \\
\hline 5 & $\mathrm{~F}$ & 7.1 & 3 & -5.94 & $8.0 \%$ & $\mathrm{~d} 4 \mathrm{~T} / 3 \mathrm{TC} / \mathrm{EFV}$ & 06 & 32.0 & 24.0 & 11.7 & Chronic gastroenteritis \\
\hline 6 & $\mathrm{~F}$ & 0.8 & 3 & -7.50 & $6.0 \%$ & $\mathrm{~d} 4 \mathrm{~T} / 3 \mathrm{TC} / \mathrm{Kal}$ & 01 & 26.0 & 116.0 & 7.0 & Chronic gastroenteritis \\
\hline 7 & $\mathrm{~F}$ & 1.5 & 4 & -5.42 & $27.0 \%$ & $\mathrm{~d} 4 \mathrm{~T} / 3 \mathrm{TC} / \mathrm{RTV}$ & 05 & 28.0 & 53.0 & 10.2 & TB Abdomen \\
\hline 8 & $\mathrm{~F}$ & 13.4 & 3 & -9.51 & $2.1 \%$ & $\mathrm{~d} 4 \mathrm{~T} / 3 \mathrm{TC} / \mathrm{EFV}$ & 02 & - & - & 10.1 & Chronic gastroenteritis \\
\hline 9 & $M$ & 0.5 & 4 & -5.24 & $4.0 \%$ & $\mathrm{~d} 4 \mathrm{~T} / 3 \mathrm{TC} / \mathrm{Kal}$ & 05 & 25.0 & 45.0 & 11.7 & Chronic gastroenteritis \\
\hline 10 & $M$ & 6.3 & 3 & - & $1.1 \%$ & AZT/3TC/EFV & 05 & 39.0 & 16.0 & 9.3 & Chronic gastroenteritis \\
\hline 11 & $M$ & 12.2 & 3 & -6.95 & $1.0 \%$ & $\mathrm{~d} 4 \mathrm{~T} / 3 \mathrm{TC} / \mathrm{EFV}$ & 06 & - & - & 5.6 & Suspected PCP \\
\hline 12 & $\mathrm{~F}$ & 1.1 & 3 & -0.87 & $1.0 \%$ & $\mathrm{~d} 4 \mathrm{~T} / 3 \mathrm{TC} / \mathrm{Kal}$ & 01 & 19.0 & 8.0 & 4.1 & Sepsis syndrome \\
\hline 13 & $M$ & 5.2 & 3 & -6.71 & $0.5 \%$ & $\mathrm{~d} 4 \mathrm{~T} / 3 \mathrm{TC} / \mathrm{EFV}$ & 08 & 28.0 & 8.3 & 7.0 & Respiratory tract infection \\
\hline
\end{tabular}

d4T, stavudine; 3TC, lamivdine; AZT, zidovudine; ddl, didanosine; EFV, efavirenz; RTV, Ritonavir; Kal, Kaletra ${ }^{\mathrm{TM}}$

from child-centered to family-centered in order to protect the integrity of caregiving structures and prevent the negative paediatric outcomes associated with the declining health or death of a primary caregiver [48]. Recruiting untested caregivers for testing and extending treatment opportunities to the caregivers who test positive is a necessary step towards protecting the future health and wellbeing of the paediatric patient.

\section{Competing interests}

The author(s) declare that they have no competing interests.

\section{Authors' contributions}

All authors read and approved the final manuscript. AR, SCL, and JG conceived the project. AR and SCL collected and analyzed the data, and co-drafted the manuscript which was commented on by all the authors. AG was the statistician for this project. RG, QAK, and NR throughout the study provided critical discussions on the manuscript. KHF, GLD, WJV, MM were the physicians that treated the children. MT developed the adherence counseling program for the clinic. KLN was the manager of the monitoring and evaluation program in the clinic. HLH and HMC wrote the grant to obtain funding for HAART scale-up. HMC and JG were senior contributors for this project and contributed equally.

\section{Acknowledgements}

We thank the families and children enrolled in our clinic. We acknowledge PEPFAR funding administered by the Elizabeth Glaser Paediatric AIDS Foundation. Anand Reddi was supported by a J. William Fulbright Scholarship. Sarah C. Leeper was supported by a Lewis Hine Documentary Fellowship from Duke University and the Bernard van Leer Foundation.

Note added in proof: In late 2006, Sinikithemba clinic was accredited by the KwaZulu-Natal provincial Department of Health as an official "antiretroviral rollout site." The government will assume responsibility for funding the site after PEPFAR funding terminates in 2007.
Note new literature added in proof: Since the initial submission of this publication, Msellati and colleagues in Côte d'Ivoire, Eley et al. in South Africa, and the AIDS Working Group of Medecins Sans Frontieres have published longer-term experience from their paediatric antiretroviral cohorts $[19,43,49]$.

\section{References}

I. AIDS epidemic update: December 2005. Geneva , United Nations Programme on HIVIAIDS (UNAIDS) and the World Health Organization; 2005.

2. Starr SE, Fletcher CV, Spector SA, Yong FH, Fenton T, Brundage RC, Manion D, Ruiz N, Gersten M, Becker M, McNamara J, Mofenson LM, Purdue L, Siminski S, Graham B, Kornhauser DM, Fiske W, Vincent C, Lischner HW, Dankner WM, Flynn PM: Combination therapy with efavirenz, nelfinavir, and nucleoside reverse-transcriptase inhibitors in children infected with human immunodeficiency virus type I. Pediatric AIDS Clinical Trials Group 382 Team. N Engl J Med I999, 34 I(25): |874-I88I.

3. van Rossum AM, Geelen SP, Hartwig NG, Wolfs TF, Weemaes CM, Scherpbier HJ, van Lochem EG, Hop WC, Schutten M, Osterhaus AD, Burger DM, de Groot R: Results of 2 years of treatment with protease-inhibitor--containing antiretroviral therapy in dutch children infected with human immunodeficiency virus type I. Clin Infect Dis 2002, 34(7): 1008-1016.

4. Resino S, Resino R, Maria Bellon J, Micheloud D, Gutierrez MD, de Jose MI, Ramos JT, Fontelos PM, Ciria L, Munoz-Fernandez MA: Clinical outcomes improve with highly active antiretroviral therapy in vertically HIV type-I-infected children. Clin Infect Dis 2006, 43(2):243-252.

5. Canani RB, Spagnuolo MI, Cirillo P, Guarino A: Decreased needs for hospital care and antibiotics in children with advanced HIV-I disease after protease inhibitor-containing combination therapy. AIDS 1999, I3(8): 1005-1006.

6. Gortmaker SL, Hughes M, Cervia J, Brady M, Johnson GM, Seage GR 3rd, Song LY, Dankner WM, Oleske JM: Effect of combination therapy including protease inhibitors on mortality among children and adolescents infected with HIV-I. N Engl J Med 200I, 345(2I): I522-I528.

7. de Martino M, Tovo PA, Balducci M, Galli L, Gabiano C, Rezza G, Pezzotti $P$ : Reduction in mortality with availability of antiretroviral therapy for children with perinatal HIV-I infection. Italian Register for HIV Infection in Children and the Italian National AIDS Registry. JAMA 2000, 284(2): 190-197.

8. Children Left Behind: Global Stakeholders Failing to Adequately Prevent or Treat Pediatric HIVIAIDS. Washington, DC, Global AIDS Alliance; 2006.

9. Coetzee D, Hildebrand K, Boulle A, Maartens G, Louis F, Labatala V, Reuter H, Ntwana N, Goemaere E: Outcomes after two years of providing antiretroviral treatment in Khayelitsha, South Africa. AIDS 2004, I 8(6):887-895. 
10. Laurent C, Ngom Gueye NF, Ndour CT, Gueye PM, Diouf M, Diakhate N, Toure Kane NC, Laniece I, Ndir A, Vergne L, Ndoye I, Mboup S, Sow PS, Delaporte E: Long-term benefits of highly active antiretroviral therapy in Senegalese HIV-I-infected adults. J Acquir Immune Defic Syndr 2005, 38(I): I4-I7.

II. Wester CW, Kim S, Bussmann H, Avalos A, Ndwapi N, Peter TF, Gaolathe T, Mujugira A, Busang L, Vanderwarker C, Cardiello P, Johnson O, Thior I, Mazonde P, Moffat H, Essex M, Marlink R: Initial response to highly active antiretroviral therapy in HIV-ICinfected adults in a public sector treatment program in Botswana. J Acquir Immune Defic Syndr 2005, 40(3):336-343.

12. Akileswaran C, Lurie MN, Flanigan TP, Mayer KH: Lessons learned from use of highly active antiretroviral therapy in Africa. Clin Infect Dis 2005, 4I(3):376-385.

13. Severe P, Leger P, Charles M, Noel F, Bonhomme G, Bois G, George E, Kenel-Pierre S, Wright PF, Gulick R, Johnson WD Jr., Pape JW, Fitzgerald DW: Antiretroviral therapy in a thousand patients with AIDS in Haiti. N Engl J Med 2005, 353(22):2325-2334.

14. Fassinou P, Elenga N, Rouet F, Laguide R, Kouakoussui KA, Timite M, Blanche $S$, Msellati $P$ : Highly active antiretroviral therapies among HIV-I-infected children in Abidjan, Cote d'Ivoire. AIDS 2004, 18(14): 1905-1913.

15. Eley B, Nuttall J, Davies MA, Smith L, Cowburn C, Buys H, Hussey G: Initial experience of a public sector antiretroviral treatment programme for HIV-infected children and their infected parents. South African medical journal = Suid-Afrikaanse tydskrif vir geneeskunde 2004, 94(8):643-646.

16. Diack MBA, Signate Sy H, Diagne Gueye NR, Ba A, Sylla A, Diouf S, Diagne I, Sarr M, Sow HD: [Epidemiological and clinical aspects of paediatric HIV infections in Albert-Royer Paediatric Hospital (Dakar, Senegal)]. Arch Pediatr 2005, I 2(4):404-409.

17. Cowburn CA, Hatherill M, Eley B, Nuttall J, Hussey G, Reynolds L, Waggie Z, Vivian L, Argent A: Short-term mortality and implementation of antiretroviral treatment for critically ill HIVinfected children in a developing country. Arch Dis Child 2006.

18. van Kooten Niekerk NK, Knies MM, Howard J, Rabie H, Zeier M, van Rensburg A, Frans N, Schaaf HS, Fatti G, Little F, Cotton MF: The first 5 years of the family clinic for HIV at Tygerberg Hospital: family demographics, survival of children and early impact of antiretroviral therapy. Journal of tropical pediatrics 2006, 52(1):3-1I.

19. O'Brien D P, Sauvageot D, Zachariah R, Humblet P: In resourcelimited settings good early outcomes can be achieved in children using adult fixed-dose combination antiretroviral therapy. AIDS 2006, 20(I5): 1955-1960.

20. Farmer P, Leandre F, Mukherjee JS, Claude M, Nevil P, Smith-Fawzi MC, Koenig SP, Castro A, Becerra MC, Sachs J, Attaran A, Kim JY Community-based approaches to HIV treatment in resource-poor settings. Lancet 200I, 358(9279):404-409.

21. Kim JY, Gilks C: Scaling up treatment--why we can't wait. $N$ Engl J Med 2005, 353(22):2392-2394.

22. Harries AD, Nyangulu DS, Hargreaves NJ, Kaluwa O, Salaniponi FM: Preventing antiretroviral anarchy in sub-Saharan Africa. Lancet 200I, 358(9279):4I0-414

23. National HIV and Syphilis Antenatal Sero-prevalence Survey in South Africa. Pretoria, Department of Health, Republic of South Africa; 2004

24. Jack C, Lalloo U, Karim QA, Karim SA, El-Sadr W, Cassol S, Friedland G: A pilot study of once-daily antiretroviral therapy integrated with tuberculosis directly observed therapy in a resource-limited setting. I Acquir Immune Defic Syndr 2004, 36(4):929-934.

25. South African Child Gauge 2005. Edited by: Jacobs MSKMSC Cape Town, Children's Institute, University of Cape Town; 2005.

26. Groenewald P, Nannan N, Bourne D, Laubscher R, Bradshaw D: Identifying deaths from AIDS in South Africa. AIDS 2005, I 9(2): 193-201.

27. Bachmann MO, Booysen FL: Relationships between HIVIAIDS, income and expenditure over time in deprived South African households. AIDS Care 2004, 16(7):817-826.

28. Guidelines for the management of HIV-infected children. Pretoria, National Deptarment of Health, South Africa; 2005.

29. Scaling up antiretroviral therapy in resouce-limited settings: treatment guidelines for a public health approach. Geneva, World Health Organization; 2006.
30. Antiretroviral Therapy: Step-by-Step guide for the Management of Children on ART. Dalbridge, ART Unit, Department of Health, Kwazulu-Natal; 2005.

31. Corbett AH, Lim ML, Kashuba AD: Kaletra (lopinavir/ritonavir). Ann Pharmacother 2002, 36(7-8): I 193-1203.

32. Lulu K, Berhane $Y$ : The use of simplified verbal autopsy in identifying causes of adult death in a predominantly rural population in Ethiopia. BMC Public Health 2005, 5(I):58.

33. Geddes R, Knight S, Moosa MYS, Reddi A, Uebel K, Sunpath H: A high incidence of nucleoside reverse transcriptase inhibitor (NRTI) - induced lactic acidosis in HIV-infected patients in a South African context. South African Medical Journal 2006, 96(8):722-724

34. Mellins CA, Brackis-Cott E, Dolezal C, Abrams Ej: The role of psychosocial and family factors in adherence to antiretroviral treatment in human immunodeficiency virus-infected children. Pediatr Infect Dis J 2004, 23(I I): I035-104I.

35. Nachega JB, Stein DM, Lehman DA, Hlatshwayo D, Mothopeng R, Chaisson RE, Karstaedt AS: Adherence to antiretroviral therapy in HIV-infected adults in Soweto, South Africa. AIDS Res Hum Retroviruses 2004, 20(1 0): 1053-1056.

36. Laniece I, Ciss M, Desclaux A, Diop K, Mbodj F, Ndiaye B, Sylla O, Delaporte E, Ndoye I: Adherence to HAART and its principal determinants in a cohort of Senegalese adults. AIDS 2003, I7 Suppl 3:SI03-8.

37. Coetzee D, Boulle A, Hildebrand K, Asselman V, Van Cutsem G, Goemaere E: Promoting adherence to antiretroviral therapy: the experience from a primary care setting in Khayelitsha, South Africa. AIDS 2004, I 8 Suppl 3:S27-3I.

38. van Rossum AM, Fraaij PL, de Groot R: Efficacy of highly active antiretroviral therapy in HIV-I infected children. Lancet Infect Dis 2002, 2(2):93-102.

39. Mwamburi DM, Wilson IB, Jacobson DL, Spiegelman D, Gorbach SL, Knox TA, Wanke CA: Understanding the role of HIV load in determining weight change in the era of highly active antiretroviral therapy. Clin Infect Dis 2005, 40(I):167-173.

40. Wools-Kaloustian K, Kimaiyo S, Diero L, Siika A, Sidle J, Yiannoutsos CT, Musick B, Einterz R, Fife KH, Tierney WM: Viability and effectiveness of large-scale HIV treatment initiatives in sub-Saharan Africa: experience from western Kenya. AIDS 2006, 20(I):4I-48.

4I. Nachman SA, Lindsey JC, Moye J, Stanley KE, Johnson GM, Krogstad PA, Wiznia AA: Growth of human immunodeficiency virusinfected children receiving highly active antiretroviral therapy. Pediatr Infect Dis / 2005, 24(4):352-357.

42. Verweel G, van Rossum AM, Hartwig NG, Wolfs TF, Scherpbier HJ, de Groot R: Treatment with highly active antiretroviral therapy in human immunodeficiency virus type I-infected children is associated with a sustained effect on growth. Pediatrics 2002, 109(2): E25.

43. Eley B, Davies MA, Apolles P, Cowburn C, Buys H, Zampoli M, Finlayson $\mathrm{H}$, King S, Nuttall J: Antiretroviral treatment for children. South African medical journal $=$ Suid-Afrikaanse tydskrif vir geneeskunde 2006, 96(9 Pt 2):988-993.

44. Rutstein RM, Gebo KA, Flynn PM, Fleishman JA, Sharp VL, Siberry GK, Spector SA: Immunologic function and virologic suppression among children with perinatally acquired HIV Infection on highly active antiretroviral therapy. Med Care 2005, 43(9 Suppl):IIII5-22.

45. Mannheimer S, Friedland G, Matts J, Child C, Chesney M: The consistency of adherence to antiretroviral therapy predicts biologic outcomes for human immunodeficiency virus-infected persons in clinical trials. Clin Infect Dis 2002, 34(8): I I I5-II II.

46. Elise A, France AM, Louise WM, Bata D, Francois R, Roger S, Philippe $M$ : Assessment of adherence to highly active antiretroviral therapy in a cohort of African HIV-infected children in Abidjan, Cote d'Ivoire. I Acquir Immune Defic Syndr 2005, 40(4):498-500.

47. Bourgeois A, Laurent C, Mougnutou R, Nkoue N, Lactuock B, Ciaffi L, Liegeois F, Andrieux-Meyer I, Zekeng L, Calmy A, Mpoudi-Ngole E, Delaporte $E:$ Field assessment of generic antiretroviral drugs: a prospective cohort study in Cameroon. Antivir Ther 2005, I0(2):335-341.

48. Ng'weshemi J, Urassa M, Isingo R, Mwaluko G, Ngalula J, Boerma T, Marston M, Zaba B: HIV impact on mother and child mortality 
in rural Tanzania. J Acquir Immune Defic Syndr 2003, 33(3):393-404.

49. Rouet F, Fassinou P, Inwoley A, Anaky MF, Kouakoussui A, Rouzioux $C$, Blanche S, Msellati P: Long-term survival and immuno-virological response of African HIV-I-infected children to highly active antiretroviral therapy regimens. AIDS 2006, 20(18):2315-2319.

\section{Pre-publication history}

The pre-publication history for this paper can be accessed here:

http://www.biomedcentral.com/1471-2431/7/13/prepub

Publish with Bio Med Central and every scientist can read your work free of charge

"BioMed Central will be the most significant development for disseminating the results of biomedical research in our lifetime. " Sir Paul Nurse, Cancer Research UK

Your research papers will be:

- available free of charge to the entire biomedical community

- peer reviewed and published immediately upon acceptance

- cited in PubMed and archived on PubMed Central

- yours - you keep the copyright

Submit your manuscript here:

http://www.biomedcentral.com/info/publishing_adv.asp 